\title{
Optimizing the cryopreservation of murine splenocytes for improved antigen-specific $T$ cell function in ELISPOT
}

\author{
Ekram Gad*, Lauren Rastetter, Dan Herendeen, Benjamin Curtis, Meredith Slota, Marlese Koehniein, Nora Disis \\ From Society for Immunotherapy of Cancer 28th Annual Meeting \\ National Harbor, MD, USA. 8-10 November 2013
}

ELISPOT assays are routinely used to measure immune responses of $\mathrm{T}$ cells in fresh and frozen splenocytes preparations; however, standardized methods for murine ELISPOT are not widely available. Freezing cells can significantly impact the function of $\mathrm{T}$ cells. The aim of this study was to optimize cryopreservation protocols to retain antigen-specific $\mathrm{T}$ cell function at similar levels as freshly isolated $\mathrm{T}$ cells using murine splenocytes. We examined four factors that might have an impact on cell viability and function: freezing medium, resting cells prior to freezing, temperature of the medium for initial dilution of cells after thawing and resting of cells prior to ELISPOT. FVB/N mice were vaccinated with adjuvant only (CFA/IFA) or IGF-IR peptides, previously shown to be immunogenic by ELISPOT analysis. Mouse splenocytes were cryopreserved using five different media: Medium 1 (50\% X-Vivo media, 40\% FBS, 10\% DMSO), Medium 2 (25\% RMPI, 65\% FBS, 10\% DMSO), Medium 3 (90\% FBS, 10\% DMSO), Medium 4 (Amresco Media) and Medium 5 (EZ-CP2 Media). Prior to freezing, the cells were either rested on ice for 5 hours or immediately frozen and moved to liquid nitrogen. After four weeks, we used media at $37^{\circ} \mathrm{C}$ or $4^{\circ} \mathrm{C}$ for initial dilution of cells after thawing. The thawed cells were either rested overnight at $37^{\circ} \mathrm{C}$ or not rested. The recovery efficiency and $\mathrm{T}$ cell function were evaluated by determining cell viability, background levels, peptide responses, and mitogen responses in ELISPOT assays, respectively. We observed significantly lower cell viability when using freezing Medium 4 and 5 , compared to the other media tested (Medium 5 vs Media 1-4: $\mathrm{P}<0.001$; Medium 4 vs $1: \mathrm{P}<0.001$, Medium 4 vs 2 $\mathrm{P}<0.05)$. Resting cells for 5 hours prior to freezing resulted in higher viability, however this difference was not significant $(\mathrm{P}=0.072)$. Using media warmed to $37^{\circ} \mathrm{C}$ to dilute thawed samples resulted in significantly higher cell viability as compared to using media at $4^{\circ} \mathrm{C}$ $(P<0.0001)$. Media 2 and 3 gave significantly lower background than Fresh cells $(\mathrm{P}<0.05)$. Medium 3 was the only freezing medium to result in similar levels of IGF1R peptide responses compared to Fresh. Overnight resting of cryopreserved cells before ELISPOT gave significantly lower $\mathrm{T}$ cells responses in both PHA and PMA/ionomycin controls compared to unrested cryopreserved cells $(\mathrm{P}<0.001)$. However, overnight resting of cells gave mitogen responses most similar to that of fresh cells when PHA or PMA/ionomycin controls were used. The method of cryopreservation can have a tremendous impact upon splenocytes viability and function. By using an optimized cryopreservation protocol, it is possible to obtain antigen-specific $\mathrm{T}$ cell function at levels similar to freshly isolated cells.

Published: 7 November 2013

doi:10.1186/2051-1426-1-S1-P211

Cite this article as: Gad et al:: Optimizing the cryopreservation of murine splenocytes for improved antigen-specific $T$ cell function in ELISPOT. Journal for ImmunoTherapy of Cancer 2013 1(Suppl 1):P211.

Oncology, University of Washington, Seattle, WA, USA

(c) 2013 Gad et al; licensee BioMed Central Ltd. This is an Open Access article distributed under the terms of the Creative Commons 